\title{
Design Factors for Applying Cryogen Storage and Delivery Technology to Solar Thermal Propulsion
}

Marc G. Millis

Lewis Research Center

Cleveland, Ohio

Prepared for the

Space Technology and Applications International Forum cosponsored by NASA, DSWA, U.S. DOE, and USAF Albuquerque, New Mexico, January 26-30, 1997

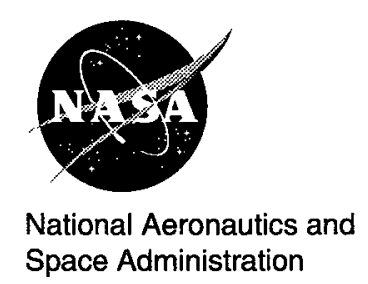




\title{
DESIGN FACTORS FOR APPLYING CRYOGEN STORAGE AND DELIVERY TECHNOLOGY TO SOLAR THERMAL PROPULSION
}

\author{
Marc G. Millis \\ NASA Lewis Research Center \\ 21000 Brookpark Rd., Cleveland, OH 44135 \\ (216) $977-7535$ \\ marc.millis@lerc.nasa.gov
}

\begin{abstract}
Thermodynamic Vent System (TVS) and Multilayer Insulation (MLI) technology, originally developed for long term storage of cryogen propellants in microgravity, is ideally suited for propellant storage and delivery systems for solar thermal propulsion. With this technology the heat-induced pressure rise in the tank provides the propellant delivery pressure without the need for an auxiliary pressurant system, and propellant delivery is used to remove the excess heat to control tank pressure. The factors to consider in designing such a balanced system are presented. An example of a minimum system design is presented along with examples of laboratory-tested hardware.
\end{abstract}

\section{INTRODUCTION}

Solar thermal propulsion is being investigated for orbit transfer applications. Two such programs are the Solar Thermal Upper Stage Technology Demonstrator (STUSTD) managed by Marshall Space Flight Center (Cady 1996a), and the Integrated Solar Upper Stage (ISUS) managed by the Air Force Phillips Labs (Jacox 1996).

Because of the high specific impulse achievable using hydrogen, it is the propellant of choice for solar thermal propulsion. To increase hydrogen's storage density, it must be stored as liquid. Since solar thermal orbit transfers are relatively long (30 days or more), special technology is required for the long-duration storage of cryogens. Fortunately, the same technology developed for long-duration storage of cryogen propellants can also be used in the design of propellant delivery systems for solar thermal propulsion. By using the cryogen storage technology to also provide the propellant delivery function, the solar thermal vehicle will not need the extra complexity, weight, and cost of an auxiliary pressurant system. This paper explains the methods and trades for applying this cryogen storage technology to future solar thermal propulsion applications.

\section{BACKGROUND}

For storing cryogens in space for long durations with minimal boiloff loss, two key technologies have been developed; Multilayer Insulation (MLI) and Thermodynamic Vent Systems (TVS) (Knoll 1991, Stark 1967, Bullard 1972, Aydelott 1985). MLI typically consists of alternating layers of aluminized mylar and low conductivity spacer material that covers the storage tank to minimize the heat input into the tank. A TVS system typically consists of a Joule-Thomson expansion valve (J-T) and heat exchanger in the vent line of the tank (Lin 1991). When the stored cryogen is vented through the J-T expander and then through the heat exchanger, a refrigeration effect is created that cools the remaining liquid in the tank. Also, a fluid mixer is typically

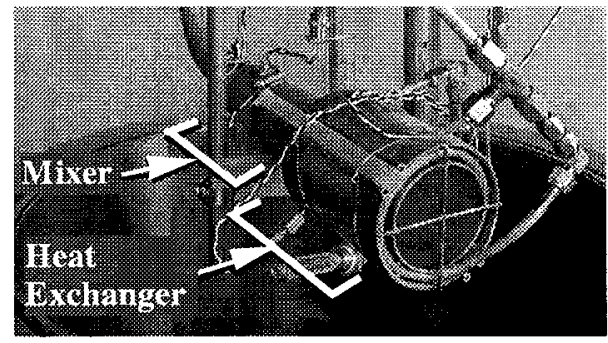

FIGURE 1. Typical TVS Components (Stats: $6.4 \mathrm{~kg}$ mass, $180 \mathrm{~W}$ heat removal rate, 0.43 $\mathrm{gm} / \mathrm{s}$ flow, $39 \mathrm{l} / \mathrm{min}$ mixer flow)

included in the system to provide some control of the heat removal process and for destratifying the stored fluid when required. Figure 1 shows a photograph of typical laboratory TVS components (Seigneur 1993).

\section{KEY APPLICATION FACTORS}

The primary design challenge for applying long-duration cryogen storage technology to solar thermal missions is to balance the design of the MLI and the TVS to meet the mission profile. The MLI design must be tailored to allow the just enough heat into the tank needed for self-pressurization, while the TVS design 
must be tailored to provide the required propellant flow rate and simultaneously remove the required amount of heat from the tank to maintain a safe tank pressure. Because of the low flow rates and relatively long orbit transfers of solar thermal propulsion, this balance can be achieved. In the ISUS mission, for example (Jacox 1996), the flow rate is approximately $5 \mathrm{gm} / \mathrm{sec}$ and thrusting occurs roughly once per orbit over the 30 day orbit transfer. Thrusting durations range from about 4 minutes to about 15 minutes, and the time between thrustings ranges from 1-1/2 hours to about 10 hours. When the vehicle is not thrusting, the propellant tank is "locked-up" -- no propellant is vented. This time is used to allow the tank to self-pressurize from passive heating. During thrusting, propellant and heat are removed from the tank by operating the TVS system.

Specifically, the propellant storage and delivery system must be designed such that the pressure drop in the tank that occurs during a given thrusting period balances with the anticipated pressure rise that will occur in the following lock-up period so that the delivery pressure is recovered just prior to the start of the next thrusting. The pressure drop during thrusting is a function of propellant removed and the amount of heat removed with the TVS system. The pressure rise during lock-up is driven by the design of the tank's insulation, the duration of the lock-up period, and the amount of liquid remaining in the tank. These factors and their associated design margins are discussed next.

To illustrate the relation between the rising pressure during the lock-up duration and the falling pressure during thrusting, refer to Figure 2 which is based on Equation 1. This figure plots the ratio of the lock-up duration to thrusting duration versus the propellant flow rate during thrusting. The diagonal line is where the pressure rise is exactly balanced with the pressure drop, without the operation of a TVS or a heater. Conditions above this line are where a heater would be required since the pressure drop during thrusting will be greater than that which can be recovered with background heating alone. Conversely, conditions below this balance line are where heat needs to be removed from the tank since the pressure rise during the lock-up will be greater than that which can be compensated by liquid venting alone. In such cases the operation of a TVS is required.

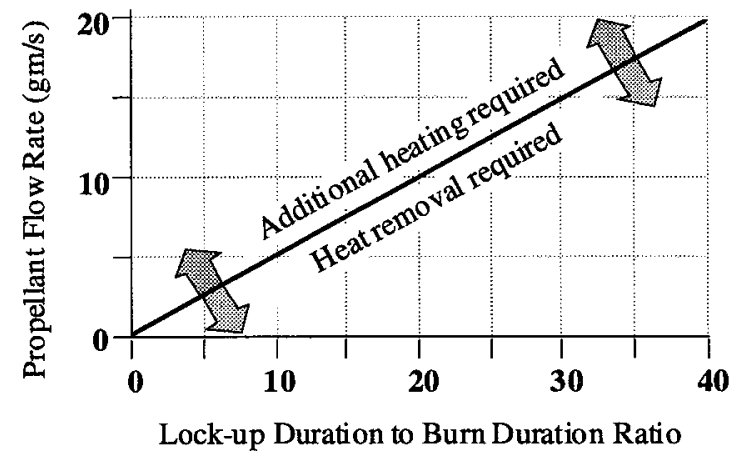

FIGURE 2. Balance Heat in with Propellant Out to Sustain Tank Pressure (Assumes $0.30 \mathrm{Mpa}$ tank pressure, $12 \mathrm{~W}$ heat rate, and $100 \%$ liquid vented)

This balanced condition is calculated from the following thermodynamic equation based on the homogeneous model (Jacox 1996):

$$
\mathrm{mh}_{\mathrm{fg}}\left(\mathrm{x}+\rho_{\mathrm{v}} /\left(\rho_{l}-\rho_{\mathrm{V}}\right)\right)=\mathrm{Q}_{\mathrm{W}}\left(1+\mathrm{t}_{\mathrm{L}} \mathrm{t}_{\mathrm{T}}\right)
$$

where $m$ is the propellant outflow rate, $h_{f g}$ is the latent heat of vaporization, $x$ is the quality of fluid leaving the tank ( $x=0$ for saturated liquid and $x=1$ for saturated vapor), $\rho_{v}$ and $\rho_{1}$ are the densities of saturated vapor and liquid in the tank respectively which are both a function of tank pressure, $Q_{W}$ is the heat rate into the tank, and $t_{\mathrm{L}}$ and $\mathrm{t}_{\mathrm{T}}$ are the lock-up and thrusting durations respectively.

\section{Thermodynamic Vent System}

When including the operation of the TVS into the equation, the new equation representing the balance between the heat into the tank and the heat removed by the TVS and the propellant mass removal becomes (Jacox 1996):

$$
\mathrm{Q}_{\mathrm{W}} \mathrm{t}_{\mathrm{L}}+\mathrm{Q}_{\mathrm{W}} \mathrm{t}_{\mathrm{T}}=\left(\mathrm{Q}_{\mathrm{tvs}}+\mathrm{mh}_{\mathrm{fg}}\left(\rho_{\mathrm{v}} /\left(\rho_{1}-\rho_{\mathrm{v}}\right)\right)\right) \mathbf{t}_{\mathrm{T}}
$$

where $\mathrm{Q}_{\mathrm{tvs}}$ is the cooling capacity required of the TVS, and the other terms are as before. This equation is based on simplified thermodynamic equations for designing and analyzing the performance of TVS and fluid mixers (Lin 1991). 
Since it is unlikely that the flow rate and the ratio of the lock-up to thrusting duration will all be fixed for a given mission, a solar thermal TVS will have to have an adjustable heat removal capacity, $Q_{\text {tvs. }}$. This calls for an "Active TVS." An active TVS has a mixer as an integral component to its heat exchanger. The mixer drives the flow of the bulk fluid in the tank through one leg of the heat exchanger, while the other leg of the heat exchanger contains the venting flow downstream of the J-T expander. By varying the run time of the mixer during propellant flows, the heat removal rate of the TVS can be adjusted.

\section{Self-Pressurization From Background Heating}

When the tank is locked-up between thrusting, the background heat that enters the tank through the MLI will cause the pressure to rise. The MLI system can be designed to provide the desired heat rate into the tank, $Q_{W}$, and a heater on the tank can be used to augment this heat rate if needed. Theoretical predictions and laboratory data exist to predict the actual heat flux across a tank wall for various numbers of layers of MLI, including the effect of tank supports and penetrations. Figure 3 is an encapsulation of this theory and ground test data (Knoll 1991), and takes into account the effects of the lower ambient temperature in space as the hot side boundary condition (Stochl 1991). Even though

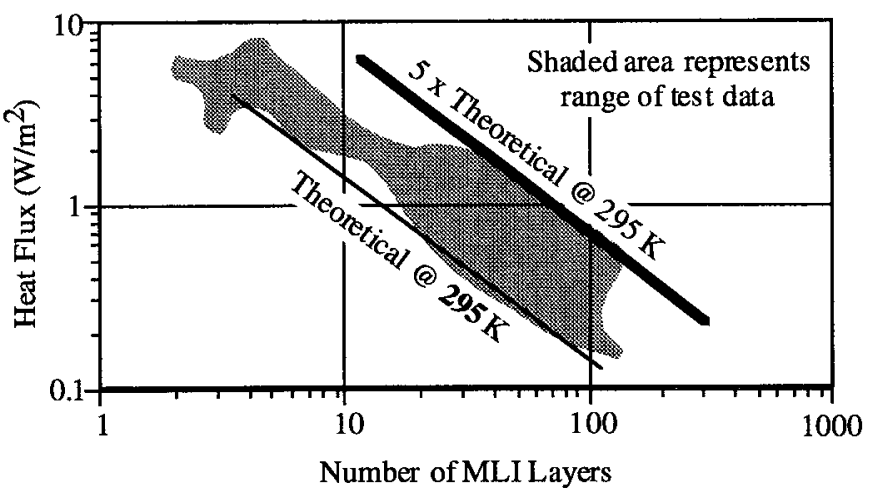

FIGURE 3. MLI Actual and Theoretical Performance (Assuming a $295 \mathrm{~K}$ background temperature) theory and laboratory data exist to predict the thermal performance of a cryogen storage tank, these predictions are not exact, and it is prudent to design margin into any actual system.

To determine what $Q_{W}$ is required, the homogeneous pressure rise rate equation can be used as an initial estimate. This equation represents the lowest rate at which the pressure will rise under normal gravity, 1-g, conditions. In practice the actual pressure rise rate is higher than this homogeneous rate in normal gravity. By operating a mixer to thermally destratify the fluid, the pressure rise rate can be made to approach this homogeneous rate (Lin 1991).

$$
\mathrm{dP} / \mathrm{dt}=\phi \mathrm{Q}_{\mathrm{W}} / \mathrm{V}
$$

where $\mathrm{Q}_{\mathrm{W}}$ is the heat rate into the tank which is a function of the background temperature and the tank's insulation, $V$ is the volume of the tank and $\phi$ is the energy derivative which is a function of the tank pressure and the average fluid density at saturated, two phase conditions. The effect of the energy derivative, $\phi$, on the pressure rise rate is that the pressure rise rate will be greater for low liquid fill levels than for high liquid fill levels. This means that near the end of the orbit transfer, when the tank is nearing empty, the pressure will rise more quickly than it did earlier in the orbit transfer. When designing a cryogen storage system, therefore, the required amount of insulation should be calculated for the conditions at the latter stages of the orbit transfer.

In the microgravity environment of orbit the actual pressure rise rate may be lower than the homogeneous rate (Lin 1992). A factor that may affect the actual pressure rise is tank surface wetting. During the early portions of the orbit transfer when the tank is nearly full, it is possible that the entire inside surface of the tank is in contact with liquid while the vapor forms a bubble that is not in contact with the walls. The pressure rise rate will be less under these conditions. Flight tests with simulant fluids have shown that conditions can occur where the liquid becomes superheated, followed by sudden pressure rises (Hasan, 1993 \& 1996). By using a mixer, the pressure rise rate can be made to approach the homogeneous rate. 


\section{Design Margin}

Given the uncertainties about the actual heat rate and the resulting pressure rise rate, an actual system must be designed to accommodate these uncertainties. In particular these uncertainties can be accommodated by having a heater on the tank to add extra heat if required, a mixer to thermally destratify the fluid while the tank is locked-up, and an adjustable TVS whose heat removal rate can be tuned to suit the orbit transfer thrusting schedule. The controller that runs the heater, mixer and TVS must have the flexibility to accommodate these variations. The controller will require accurate pressure and propellant flow rate instrumentation to adequately track and respond to the required tank pressure.

\section{Other Factors}

For solar thermal vehicles, the hydrogen tank occupies a significant volume. To minimize tank volume and tank weight it is desirable to have a low initial ullage volume and a low pressure rating for the tank. Ullage is the portion of vapor in a cryogen tank. Although initial ullages as low as $1 \%$ of tank volume are conceivable, possible errors in tank fill levels and measured tank pressure make it prudent to use a larger, safer ullage, no less than $3 \%$, preferably $5 \%$ or $10 \%$. For a given ullage and saturated conditions for LH2, the volume of the propellant tank gets smaller for lower tank pressures. This fact is reflected in the hydrogen properties outlined in Table 1. A low tank pressure rating also allows lighter-weight tank construction. Although a low tank pressure is attractive for minimizing tank volume and weight, it correspondingly lowers the propellant delivery pressure. Trades must be performed to determine the optimum combination of tank volume, weight, and propellant delivery pressure. For comparison, the ISUS system has a baseline tank pressure of $0.30 \mathrm{MPa}$, and a delivery pressure to the thruster of $>0.15 \mathrm{MPa}$ (Jacox 1996).

TABLE 1. Saturated Liquid Hydrogen Density and Pressure Properties.

\begin{tabular}{|c|c|}
\hline Pressure (MPa) & Density $\left(\mathbf{k g} / \mathbf{m}^{\mathbf{3}}\right)$ \\
\hline 0.50 & 60.8 \\
\hline 0.40 & 62.9 \\
\hline 0.30 & 65.2 \\
\hline
\end{tabular}

On the launch pad, where atmospheric pressure surrounds the tank, the insulating performance of the MLI is degraded. To improve this situation, a Helium filled purge bag can be used around the tank. During launch, the atmospheric pressure around the tank drops rapidly so that the heat loads during ascent are not significant.

\section{EXAMPLE MINIMUM SYSTEM}

Figure 4 shows a schematic of a typical minimum TVS delivery system suitable for solar thermal missions. Starting from left to right, there is a liquid acquisition start basket to insure that liquid enters the system, followed by the J-T expander and then the heat exchanger to remove heat from the tank, then out through the tank wall to an on/off control valve and then into the thruster. The secondary leg of the heat exchanger, with an integral mixer, uses fluid from the bulk volume of the tank. Standard fill, drain, and relief functions are also shown on the schematic. During TVS operation, when propellant

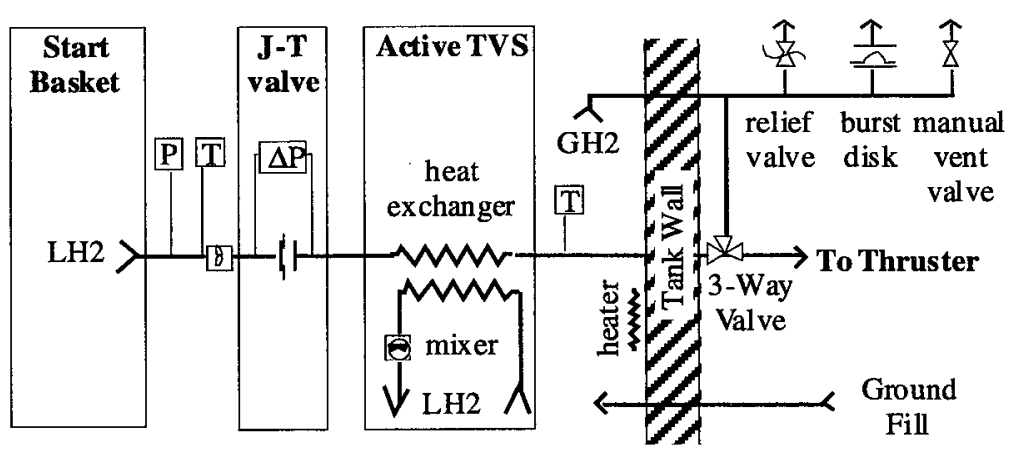

$\Delta \mathrm{P}$ Delta Pressure Sensor

P Pressure Sensor

T Temperature Sensor

\| Joule-Thomson Valve

FIGURE 4. Minimum TVS Propellant Delivery System.

is flowing to the thruster, running the mixer will increase the heat removal through the heat exchanger. Under no-flow conditions, the mixer can be used to destratify the fluid in the tank to affect tank pressure. 
Note that a start basket is used to perform the role of liquid acquisition. Since the tank will be accelerated during thrusting, the propellant will settle rather rapidly forgoing the need for larger liquid acquisition (LAD) devices. The start basket can be sized to insure that enough liquid is fed into the delivery system for the earliest portion of a thrusting before the propellant settles. Other solar thermal TVS systems use a larger LAD with an integral passive TVS heat exchanger (Cady 1996a \& 1996b). This is an option that may also be employed.

To measure propellant flow, two different methods are shown on the schematic. One flow measurement simply uses a delta pressure measurement across the J-T expander. The other uses a turbine flowmeter. Actual flow rates and pressures for a given application should drive the selection of which method is best for that application.

\section{TYPICAL SYSTEM TESTING REQUIREMENTS}

The technology for the TVS delivery system and MLI insulation has been sufficiently developed to allow designing propellant storage and delivery systems for solar thermal missions. To help reduce the span of required design margins and to build confidence in the supporting technology, a flight test is recommended to validate the TVS technology in the microgravity environment. Regardless of further testing of TVS technology, some ground testing will still be required to verify the point design performance of systems, determine the required operating margins, and to verify operation of the system controls. Design point testing will be required to determine actual tank thermal properties, calibration of the Joule-Thomson valve, performance mapping of the heat exchanger, coupled testing of the delivery system with the thruster, and testing to evaluate, select, and verify the flow control method. The tank thermal properties can be determined by boil-off tests as a function of fill level to determine heating rate, and/or self pressurization as a function of fill level. Although J-T expander valves are off-the-shelf technology, it will be necessary to calibrate the chosen commercial J-T valve over the operational range of pressure drops and flow rates for a given application. This is critical to insure the required flow rate accuracy. To demonstrate system performance including that of the flow control methods, it will be necessary to conduct an in-line test of the delivery system coupled to the thruster. This will determine the flow control accuracies, system transients, and verify operational characteristics, including the required flexibility to accommodate variations in thrusting schedule and to compensate for variations in the actual heating of the tank and other uncertainties.

\section{CONCLUSIONS}

Thermodynamic Vent System and Multilayer Insulation technology is ideally suited for propellant storage and delivery systems for solar thermal propulsion. By using this technology, the extra mass, complexity, and cost of auxiliary pressurant systems can be avoided. Enough margin and system control variables exist with which to design a variety of applications and still accommodate variations of heat rates, pressure rise rates, and propellant flow rates.

\section{Acknowledgments}

The author wishes to thank Mojib Hasan for his tutelage and significant contributions in the analysis and design of the TVS, in particular for deriving equations 1 and 2, and to Dave Plachta for the analysis of MLI performance. This paper is based largely on that work which was originally done to support the ISUS system definition study. Thanks is also owed to Neil Van Dresar and Joseph Gaby for their editorial services in completing this report.

\section{References}

Aydelott, J., Carney M. and Hochstien, J. (1985) "NASA Lewis Research Center Low-Gravity Fluid Management Technology Program," NASA TM-87145, NASA Lewis Research Center.

Bullard, B. (1972) "Liquid Propellant Thermal Conditioning System Test Program," NASA CR-72971, LMSC-D159262, Lockheed Missiles and Space Co.

Cady, E. and Olsen, A. Jr. (1996) "Solar Thermal Upper Stage Technology Demonstrator Program," AIAA 963011, 32nd AIAA/ASME/SAE/ASEE Joint Propulsion Conference. 
Cady, E. and Olsen, A. Jr. (1996) "Cryogen Storage and Propellant Feed System for the Integrated Solar Upper Stage (ISUS) Program," AIAA 96-3044, 32nd AIAA/ASME/SAE/ASEE Joint Propulsion Conference.

Hasan, M. et al. (1993) "Nucleate Pool Boiling in the Long Duration Low Gravity Environment of the Space Shuttle," NASA TM 105973, NASA Lewis Research Center.

Hasan, M., Lin, C., Knoll, R. and Bentz, M. (1996) "Tank Pressure Control Experiment: Thermal Phenomena in Microgravity," NASA TP-3564, NASA Lewis Research Center.

Jacox, M., Kennedy, F., Malloy J., Merk, C. and Miller, T. (1996) "Integrated Solar Upper Stage (ISUS) Space Demonstration System Definition Study," PL-TR-96-1006, Phillips Laboratory, Kirtland AFB.

Knoll, R., Stochl, R., and Sanabria, R. (1991) "A Review of Candidate Multilayer Insulation Systems for Potential Use on Wet-Launched $\mathrm{LH}_{2}$ Tankage for the Space Exploration Initiative Lunar Missions", NASA TM 104493, NASA Lewis Research Center.

Lin, C., Van Dresar, N., and Hasan, M. (1991) "A Pressure Control Analysis of Cryogenic Storage System," AIAA 91-2405, 27th AIAA/ASME/SAE/ASEE Joint Propulsion Conference.

Lin, C. and Hasan, M. (1992) "Self-Pressurization of a Spherical Liquid Hydrogen Tank in a Microgravity Environment," AIAA 92-0363, 28th AIAA/ASME/SAE/ASEE Joint Propulsion Conference

Seigneur, A. (1993) "Design, Analysis, Fabrication, and Testing of an Active Heat Exchanger for Use in Cryogenic Fluids," Masters Thesis, Dept of Mechanical Engineering, Cleveland State Univ.

Stark, J. and Blatt, M. (1967) "Zero Gravity Prototype Vent System," GD/C, NASS-20146, GDC-DDB67-006.

Stochl, R. and Knoll, R. (1991) "Thermal Performance of a Liquid Hydrogen Tank Multilayer Insulation System at Warm Boundary Temperatures of 630, 530, and $152^{\circ} \mathrm{R}^{\prime \prime}$, AIAA-91-2400, 27th Joint Propulsion Conference.

$\begin{array}{ll} & \\ \text { STUSTD } & \text { Solar Thermal Upper Stage Technology Demonstrator } \\ \text { ISUS: } & \text { Integrated Solar Upper Stage } \\ \text { MLI: } & \text { Multilayer Insulation } \\ \text { TVS: } & \text { Thermodynamic Vent System } \\ \text { J-T: } & \text { Joule-Thomson valve } \\ \text { LAD: } & \text { Liquid Acquisition Device } \\ \text { LH2: } & \text { Liquid Hydrogen } \\ \mathbf{h}_{\mathrm{fg}}: & \text { Latent heat of vaporization (Joule/kg) } \\ \mathrm{m}^{\mathrm{m}}: & \text { Propellant outflow rate }(\mathrm{kg} / \mathrm{s}) \\ \mathrm{Q}_{\mathrm{W}}: & \text { Heat rate into tank }(\mathrm{W}) \\ \mathrm{Q}_{\mathrm{tvs}}: & \text { Cooling capacity required of the TVS }(\mathrm{W}) \\ \mathrm{t}_{\mathrm{L}}: & \text { Tank lock-up duration with no venting }(\mathrm{sec}) \\ \mathrm{t}_{\mathrm{T}}: & \text { Thrusting duration (sec) } \\ \mathrm{x}: & \text { Quality of saturated fluid leaving the tank }(\mathrm{x}=0 \text { for liquid, } \mathrm{x}=1 \text { for vapor) } \\ \rho_{\mathrm{v}}: & \text { Density of saturated vapor }\left(\mathrm{kg} / \mathrm{m}^{3}\right) \\ \rho_{\mathrm{l}}: & \text { Density of saturated liquid }\left(\mathrm{kg} / \mathrm{m}^{3}\right) \\ \phi & \left.\text { Energy derivative (Pa } \mathrm{m}^{3} / \mathrm{Joules}\right)\end{array}$


Public reporting burden for this collection of information is estimated to average 1 hour per response, including the time tor reviewing instructions, searching existing data sources, gathering and maintaining the data needed, and completing and reviewing the collection of information. Send comments regarding this burden estimate or any other aspect of this Davis Highway, Suite 1204, Arlington, VA 22202-4302, and to the Office of Management and Budget, Paperwork Reduction Project (0704-0188), Washington, DC 20503.
1. AGENCY USE ONLY (Leave blank)
2. REPORT DATE
3. REPORT TYPE AND DATES COVERED
December 1996
Technical Memorandum

4. TITLE AND SUBTITLE

5. FUNDING NUMBERS

Design Factors for Applying Cryogen Storage and Delivery Technology to Solar

Thermal Propulsion

6. AUTHOR(S)

Marc G. Millis

WU-233-1A-BY

7. PERFORMING ORGANIZATION NAME(S) AND ADDRESS(ES)

8. PERFORMING ORGANIZATION REPORT NUMBER

National Aeronautics and Space Administration

Lewis Research Center

Cleveland, Ohio 44135-3191

E-10567

9. SPONSORING/MONITORING AGENCY NAME(S) AND ADDRESS(ES)

10. SPONSORING/MONITORING AGENCY REPORT NUMBER

National Aeronautics and Space Administration

Washington, DC 20546-0001

NASA TM-107379

11. SUPPLEMENTARY NOTES

Prepared for the Space Technology and Applications International Forum cosponsored by NASA, DSWA, U.S. DOE, and USAF, Albuquerque, New Mexico, January 26-30, 1997. Responsible person, Marc G. Millis, organization code, 5340, (216) 977-7535.

12a. DISTRIBUTION/AVAILABILITY STATEMENT

12b. DISTRIBUTION CODE

Unclassified - Unlimited

Subject Category 70

This publication is available from the NASA Center for AeroSpace Information, (301) 621-0390.

13. ABSTRACT (Maximum 200 words)

Thermodynamic Vent System (TVS) and Multilayer Insulation (MLI) technology, originally developed for long term storage of cryogen propellants in microgravity, is ideally suited for propellant storage and delivery systems for solar thermal propulsion. With this technology the heat-induced pressure rise in the tank provides the propellant delivery pressure without the need for an auxiliary pressurant system, and propellant delivery is use to remove the excess heat to control tank pressure. The factors to consider in designing such a balanced system, are presented. An example of a minimum system design is presented along with examples of laboratory-tested hardware.

14. SUBJECT TERMS

Space propulsion; Cryogenic fluid management; Liquid hydrogen

15. NUMBER OF PAGES

08

16. PRICE CODE

A02

17. SECURITY CLASSIFICATION
OF REPORT
Unclassified

18. SECURITY CLASSIFICATION OF THIS PAGE Unclassified

19. SECURITY CLASSIFICATION OF ABSTRACT

20. LIMITATION OF ABSTRACT 